\title{
Azadirachta excelsa Improves Renal Morphology and Function in Streptozotocin Induced-Diabetic Sprague Dawley Rats
}

\author{
Nur Syimal Aain AZMI", Nooraain HASHIM, Nurdiana SAMSULRIZAL, \\ Noor Syaffinaz NOOR and Mohamad ZIN
}

Faculty of Applied Sciences, Universiti Teknologi MARA, Selangor, Malaysia

('Corresponding author's e-mail: syimalainazmi@gmail.com)

Received: 1 December, 2018, Revised: 1 January 2020, Accepted: 1 February 2020

\begin{abstract}
Long term diabetes mellitus (DM) is associated with serious complications such as nephropathy. Previous studies revealed the ability of $A$. excelsa leaf extract treatment to reduce fasting blood glucose (FBG) in streptozotocin (STZ)-induced diabetic rats. The aim of this study was to determine the effect of $A$. excelsa extract in delaying the progression of diabetic nephropathy by evaluating the kidney structure and function. The effects were compared with 2 positive controls, which were metformin (standard drug) and quercetin (plant active compound). Induction of diabetic conditions was conducted by the intraperitoneal (IP) injection of STZ (60 mg/kg bwt) in male Sprague Dawley rats. The experimental animals were grouped into: 1) normal control (NC, saline); 2) diabetic control (DC, saline); 3 ) metformintreated diabetic rats (DMET, $1000 \mathrm{mg} / \mathrm{kg} \mathrm{bwt}$ ); 4) quercetin-treated diabetic rats (DQ, $40 \mathrm{mg} / \mathrm{kg}$ bwt), and 5) $A$. excelsa-treated diabetic rats (DAE, $250 \mathrm{mg} / \mathrm{kg}$ bwt). All treatments were given once daily for 8 weeks through oral gavage. The inter-relation between the changes in the fasting blood glucose and kidney oxidative stress, structure, and function was evaluated. The results showed a significant increase $(p<0.05)$ of MDA and SOD level and a decrease $(p<0.05)$ of GPx levels, plus distortion of renal morphology among the DC and DMET groups. Meanwhile, both DQ and DAE groups showed significant reduction $(p<0.05)$ of MDA levels and elevation $(p<0.05)$ of SOD and GPx levels. The quercetin and $A$. excelsa treatments also improved the kidney function parameters and morphological changes of the diabetic rats. These findings indicate that quercetin and $A$. excelsa possess renal therapeutic effects.
\end{abstract}

Keywords: Nephropathy, Streptozotocin, MDA, GPx, SOD, Kidney function parameters

\section{Introduction}

One of the most common endocrine and metabolic disorders seen in developing countries is diabetes mellitus (DM). Diabetes has taken on epidemic proportions, with global prevalence estimates of 382 million people [1]. DM is one of the main causes of nephropathy, rising creatinine levels, and Chronic Kidney Disease (CKD), and ultimately leads to End-Stage Renal Disease (ESRD) [2,3]. CKD is a common condition that is estimated to affect over 154 million people worldwide [4]. In Malaysia, there has been an increasing trend in dialysis provision for end-stage renal disease, from 96 in 2002 to 182 cases per million population in 2011 [5]. CKD resulting from diabetes has been termed "Diabetic Kidney Disease" (DKD). It is important to note that, in most of cases, CKD or DKD is often present at the time of diabetes diagnosis [6]. One of the most important complications in which end organ injuries occur is diabetic nephropathy, which manifests in the long term. End-organ injuries occurring in DM decrease quality of life, while highly increasing medical costs and mortality rates. Kidney injury is the most common pathological disorder predisposing end-stage renal disease worldwide $[7,8]$. 
http://wjst.wu.ac.th

There is evidence to show a significant role of reactive oxygen species (ROS) in the increase of diabetic nephropathy pathogenesis $[9,10]$. Cellular damage begins to occur when the production of ROS exceeds the antioxidant capacity, through which macromolecules that exist within the cellular composition, such as proteins, lipids, and carbohydrates, are oxidized and damaged [11,12]. Overproduction of ROS causes insufficient antioxidant capacity which eventually disturbs the oxidantantioxidant balance [13]. However, various studies have depicted the alleviation of renal damage with the administration of antioxidant-rich agents $[14,15]$.

One of the molecules researched in recent studies due to its antioxidant property is quercetin [16]. Quercetin, a powerful antioxidant bioflavonoid, attenuates pancreas and renal dysfunction in long-term experimental diabetes mellitus [17,18]. A previous study also recorded that quercetin prevented diabetic kidney injury in rats [19]. A study by Zin and colleagues [20] indicated the highest composition of quercetin in the ethanolic extract of $A$. excelsa leaf as compared to kaempferol, isovitexin, vitexin, and homoorientin. Therefore, this study was carried out to assess the effect of quercetin, the active compound of $A$. excelsa, in its therapeutic potential to alleviate DM nephropathy as compared with $A$. excelsa extract.

Azadirachta excelsa, (Jack) Jacobs, is a marrango or Philippine neem tree of congenric species in Southeast Asia. Originating in Borneo, A. excelsa grows naturally in southern Thailand, peninsular Malaysia, and the Palawan island of the Philippines. In Malaysia, A. excelsa is a typical wild plant known as the marrango tree or sentang [21]. Various studies revealed the health-promoting potential of Azadirachta species, which include antioxidant, diuretic, antiviral, antiulcer, anti-malarial, antiinflammatory, and cytotoxic effects [22]. A study indicated that a GC-MS chromatogram of $A$. excelsa leaves was associated with higher plant constituents of flavonoids and moderate amounts of tannins, triterpenes, and steroids [23]. The presence of various antioxidant-rich compounds might explain the therapeutic property of $A$. excelsa. Even though the ability of $A$. excelsa to alleviate diabetes among diabetic animal models has been proven previously, its ability to ameliorate or delay the progression of secondary kidney complication remains elusive. Hence, this study aimed to evaluate the effect of $A$. excelsa on diabetic-associated kidney disease.

\section{Materials and methods}

\section{Collection and authentication of plant specimen}

The leaves of $A$. excelsa plant were collected in January, 2015, from the Forest Research Institute of Malaysia (FRIM), Kepong, Kuala Lumpur. The plant was authenticated by Mr. Sani Miran as A. excelsa with voucher number UKMB-40314, and the specimen was deposited at the Herbarium of Universiti Kebangsaan Malaysia (UKMB), Fakulti Sains dan Teknologi, Universiti Kebangsaan Malaysia, Bandar Baru Bangi, Selangor Darul Ehsan, Malaysia.

\section{Preparation of plant extract}

The leaves of the $A$. excelsa plant was washed, sliced into small pieces, and oven-dried at $37 \pm 5{ }^{\circ} \mathrm{C}$. Next, they were soaked in $70 \%$ ethanol at 1:10 ratio (100 g powder: $1000 \mathrm{~mL}$ ethanol) for 3 days at 27 ${ }^{\circ} \mathrm{C}[23,24]$. The ethanolic extract was collected in a conical flask. The mixture was filtered by using a vacuum pump, Buchner funnel, and filter papers. The filtrate obtained was evaporated by using a rotary evaporator at $40{ }^{\circ} \mathrm{C}[25]$. A dark semi-solid paste obtained was stored at $4{ }^{\circ} \mathrm{C}$ until further use.

\section{Experimental animals}

Twenty-four male Sprague Dawley rats, with body weights ranging between 150 - 200 g, aged 4 weeks old, were used in this study. The rats were attained from Chenur Supplier Sdn. Bhd., Serdang, Selangor. They were housed at the Laboratory Animal Facility and Management (LAFAM), Universiti Teknologi MARA, Puncak Alam, Selangor. The animals were acclimatized upon arrival for a week and were housed in groups of 6 and fed with a standard commercial rodent diet (Gold Coin Feedmills, Gold Coin Holdings, Malaysia) and plain water ad libitum. Experimental protocols involving the use of rats, as well as internationally-accepted practices for the usage and maintenance of laboratory animals as 
contained in the guidelines, were strictly applied. The approval reference number is UiTM CARE, $112 / 2015$.

\section{Induction of diabetes mellitus in rats}

Hyperglycemia conditions were induced at $60 \mathrm{mg} / \mathrm{kg}$ bwt in the overnight fasting male Sprague Dawley rats by conducting a single intraperitoneal (i.p.) injection of $0.5 \mathrm{~mL}$ Streptozotocin (STZ) (Sigma-Aldrich, Deisenhofen, Germany). The STZ was freshly dissolved in saline (0.9\% sodium chloride) [26]. Conversely, the age-matched normal control (NC) group received an equivalent volume of saline. Soon after the injection of STZ, the animals were given free access to food and water. In order to prevent drug-induced hypoglycemic shock, $5 \%$ glucose water was given to the rats orally by using oral gavage, repeated the next day [27]. Hyperglycemia was confirmed 1 week post STZ injection by measuring the tail vein blood glucose level with an Accu-Check glucometer. The rats with FBG levels reaching more than $11 \mathrm{mmol} / \mathrm{L}$ (Day 0) were considered diabetic [28,29]. Those that failed to develop diabetes were excluded from the study.

The reason for using the specific high-dose treatment of STZ was to induce a more rapid onset of diabetes [30]. It is known that an intraperitoneal injection of STZ leads to $\beta$-cell destruction in the pancreatic islets [31]. This consequently produces an insulin deficiency and increased blood glucose levels [32,33]. In addition, similar doses of STZ, have been employed by many researchers in other related studies.

\section{Experimental design}

The rats were divided into five groups, with six rats each (Table 1). All of the treatments were given orally once daily for a duration of 8 weeks (56 days). Quercetin was purchased from Sigma-Aldrich USA. The use of $1000 \mathrm{mg} / \mathrm{kg}$ bwt metformin for DMET group was based on a study which revealed the robust ability of this drug to improve glucose tolerance in STZ-induced diabetic rats as compared to 100 $\mathrm{mg} / \mathrm{kg}$ bwt and $300 \mathrm{mg} / \mathrm{kg}$ bwt [34]. Meanwhile, $40 \mathrm{mg} / \mathrm{kg}$ bwt of quercetin has shown a protective effect in a diabetic rat study [35]. In addition, the dose of $A$. excelsa extract was selected on the basis of our previous acute oral toxicity study. Therefore, according to the study by Nurdiana [24], $250 \mathrm{mg} / \mathrm{kg}$ of $A$. excelsa was enabled to reduce fasting blood glucose (FBG) as compared to a low dose of $100 \mathrm{mg} / \mathrm{kg}$.

Table 1 Treatment groups.

\begin{tabular}{llc}
\hline Group & Treatment & Dosage \\
\hline Normal control (NC) & Saline & - \\
Diabetic control (DC) & Saline & - \\
Diabetic rats + Metformin (DMET) & Metformin & $1,000 \mathrm{mg} / \mathrm{kg} \mathrm{bwt} \mathrm{[34]}$ \\
Diabetic rat + Quercetin (DQ) & Quercetin & $40 \mathrm{mg} / \mathrm{kg} \mathrm{bwt} \mathrm{[35]}$ \\
Diabetic rat + A. excelsa (DAE) & A. excelsa extract & $250 \mathrm{mg} / \mathrm{kg} \mathrm{bwt} \mathrm{[25]}$ \\
\hline
\end{tabular}

\section{Preparation of materials for treatment group}

The dosage for each treatment was freshly prepared with saline. The respective dosages of metformin, quercetin, and A. excelsa extract were vortexed to mix with saline. Treatments were then administered to the respective group with volume of $1 \mathrm{~mL} / 100 \mathrm{~g}$ bwt. A similar volume of saline was given to $\mathrm{NC}$ and $\mathrm{DC}$, which were the control groups. 


\section{Determination of fasting blood glucose (FBG)}

The general health and behavior of the animals were monitored during the entire period of the study. The FBG was recorded at the beginning and the end of the experiment, and the data presented the percentage change of FBG after 8 weeks of the treatment period.

\section{Urine collection}

Urine samples were collected once a week using a timely collection method $(4 \mathrm{~h})$. A timed collection method was used to measure the concentration and volume of urine over a specified length of time. In this experiment, urine was collected within $4 \mathrm{~h}$. This method was adopted from Kimura et al. [36] with minor changes. Urine specimens were stored at $-80^{\circ} \mathrm{C}$.

\section{Serum collection}

At the end of the treatments, rats were fasted overnight and anesthetized using diethyl ether. Then, blood samples $(10-15 \mathrm{~mL})$ were collected through cardiac puncture into plain red-top sterilized centrifuge tubes (BD Vacutainer ${ }^{\circledR}$, USA) containing no anticoagulants. Serum was suppurated at 4000 rpm for $15 \mathrm{~min}$ and stored at $-80^{\circ} \mathrm{C}$ until analysis.

\section{Preparation of kidney tissue homogenate}

Kidney tissue samples were homogenized in $5-10 \mathrm{~g} / \mathrm{mL}$ of phosphate buffered saline (PBS) $\left(4{ }^{\circ} \mathrm{C}\right.$, pH 7.6; Sigma Chemicals, USA). It was then centrifuged at $3000 \mathrm{rpm}$ for $15 \mathrm{~min}$ at $4{ }^{\circ} \mathrm{C}$ (Centrifuge 5417R; Eppendorf, Germany). The supernatant was then collected and stored at $-80^{\circ} \mathrm{C}$ until use.

\section{Estimation of malondialdehyde (MDA) level}

The levels of MDA equivalents were determined in the homogenate tissue of the kidney by using a TBARS assay kit (Cayman, MI, USA), as described previously [37]. The absorbance was determined at a wavelength of $540 \mathrm{~nm}$ using a spectrophotometer (Epoch 2 microplate spectrophotometer, BioTek Instruments Inc, Vermont, USA).

\section{Antioxidant enzymes activity assessment}

Glutathione peroxidase (GPx) activity was evaluated using an assay kit (Cayman, MI, USA). The experimental procedures were carried out according to the manufacturer's instructions [38]. The measurement of GPx activity was based on the rule of a coupled reaction with glutathione reductase (GR). The oxidized glutathione (GSSG) formed after reduction of hydroperoxide by GPx is recycled to its reduced state by GR in the presence of NADPH. The oxidation of NADPH is accompanied by a decrease in absorbance at $340 \mathrm{~nm}$. One unit of GPx is defined as the quantity of enzyme that catalyzes the oxidation of $1 \mathrm{nmol}$ of NADPH per minute at $25^{\circ} \mathrm{C}$.

Superoxide dismutase (SOD) activity was determined using an assay kit (Cayman, MI, USA). This kit utilizes a tetrazolium salt for the detection of superoxide radicals generated by xanthine oxidase and hypoxanthine. One unit of SOD is defined as the amount of enzyme needed to produce $50 \%$ dismutation of superoxide radical.

\section{Glomerular filtration rate (GFR) measurement}

Glomerular filtration rate (GFR) is based on creatinine clearance and was determined using urine and serum creatinine assay kits (Cayman Chemicals, Ann Arbor, MI) and urine output levels. GFR was calculated using the following formula:

$\operatorname{GFR}\left(\frac{\mathrm{ml}}{\mathrm{min}}\right)=\frac{\operatorname{Urinary} \text { creatinine }\left(\frac{\mathrm{mg}}{\mathrm{ml}}\right) \times \operatorname{Urine} \text { volume }(\mathrm{ml}) \times 1000(\mathrm{~g})}{\operatorname{Serum} \text { creatinine }\left(\frac{\mathrm{mg}}{\mathrm{ml}}\right) \times \text { body weight }(\mathrm{g}) \times 240 \mathrm{~min}}$ 


\section{Urine creatinine determination}

Urine creatinine (UCRE) was determined quantitatively using Enzyme-Linked Immunosorbent Assays (Cayman, MI, USA). Each ELISA test was conducted in triplicate and performed according to the manufacturer's protocols.

\section{Measurement of renal parameters in serum}

The levels of serum creatinine, albumin, urea, uric acid, and total bilirubin were determined spectrophotometrically using commercial diagnostic kits (Boehringer-Mannheim Diagnostic Systems) and analyzed by an auto-analyzer (Hitachi-917, Germany).

\section{Kidney histological assessment}

The kidney tissues were fixed in $4 \%$ formaldehyde embedded in paraffin blocks, sectioned at $4 \mu \mathrm{m}$, and stained with hematoxylin and eosin (H\&E). All slides were examined using light microscopy (Motic BA410, Wetzlar, Germany) equipped with a digital camera (Moticam Pro 285A, Wetzlar, Germany) under a magnification of $400 \times$.

\section{Statistical analysis}

All data were analyzed with the Statistical Package for the Social Sciences (SPSS) version 21.0 software. Data are expressed as means \pm standard error of the means (SEM) for each group of treatment. A 2-way repeated measure Analysis of Variance (ANOVA) was conducted to compare means of the time dependent parameters in the FBG. Meanwhile, 1-way ANOVA analysis was conducted for the kidney MDA, SOD, and GPx levels, GFR, and the kidney function parameters. Significant difference at $p<0.05$ were further analyzed using Duncan's multiple test.

\section{Results}

Fasting blood glucose

The means and standard errors of the means (SEM) for fasting blood glucose (FBG) in the entire groups of animals are given in Table 2. Administration of STZ had significantly higher levels of FBG by $38.70 \%(p<0.05)$ in the DC group as compared to the NC group throughout the 8 weeks period, with $20.88 \mathrm{mmol} / \mathrm{L}$ from week 0 to $28.96 \mathrm{mmol} / \mathrm{L}$ in week 8 . On the contrary, the $\mathrm{NC}$ group had a relatively constant blood glucose, ranging from 4.66 to $5.66 \mathrm{mmol} / \mathrm{L}$. Meanwhile, treatment with metformin significantly reduced the FBG level by $34.59 \%$ from 27.06 to $17.70 \mathrm{mmol} / \mathrm{L}$, while the quercetin and $A$. excelsa groups showed significant decreases of $(p<0.05)$ of FBG, by 20.83 and $27.57 \%$, respectively.

Table 2 Means of weekly fasting blood glucose level (FBG) (mmol/L) among groups throughout experimental period.

\begin{tabular}{cccc}
\hline \multirow{2}{*}{ Group } & \multicolumn{3}{c}{ Mean fasting blood glucose (mmol/L) \pm SEM } \\
\cline { 2 - 4 } & Week 0 & Week 8 & \% FBG change \\
\hline NC & $4.66 \pm 0.13^{\mathrm{a}, \mathrm{x}}$ & $5.16 \pm 0.16^{\mathrm{a}, \mathrm{x}}$ & $+10.73 \%^{\mathrm{b}}$ \\
DC & $20.88 \pm 1.37^{\mathrm{b}, \mathrm{y}}$ & $28.96 \pm 1.35^{\mathrm{c}, \mathrm{z}}$ & $+38.70^{\mathrm{c}}$ \\
DMET & $27.06 \pm 1.82^{\mathrm{c}, \mathrm{z}}$ & $17.70 \pm 1.77^{\mathrm{b}, \mathrm{y}}$ & $-34.59^{\mathrm{a}}$ \\
DQ & $28.04 \pm 1.54^{\mathrm{c}, \mathrm{z}}$ & $22.20 \pm 1.55^{\mathrm{b}, \mathrm{y}}$ & $-20.83^{\mathrm{a}}$ \\
DAE & $28.58 \pm 1.41^{\mathrm{c}, \mathrm{z}}$ & $20.70 \pm 2.19^{\mathrm{b}, \mathrm{y}}$ & $-27.57^{\mathrm{a}}$ \\
\hline
\end{tabular}

Values are means \pm SEMs. Superscripts ${ }^{\text {a,b,c,d }}$ indicate significant differences $(p<0.05)$ within same column, while superscripts ${ }^{\mathrm{x}, \mathrm{y}, \mathrm{z}}$ indicate significant differences $(p<0.05)$ between week 0 and week 8 within same row. $\mathrm{NC}=$ Normal control rats, DC $=$ Diabetic control rats, DMET $=$ Diabetic rats treated with metformin, DQ $=$ Diabetic rats treated with quercetin, DAE $=$ Diabetic rats treated with $A$. excelsa.$(+=$ addition, $-=$ reduction $)$. 


\section{Kidney oxidants and antioxidants}

The results for the effects of the treatments on kidney lipid peroxidation and the activities of antioxidant enzymes are tabulated in Table 3. There was a significant increase $(p<0.05)$ in the MDA levels of the DC, DMET, and DAE, except for the DQ, as compared with the NC group. The results reflected nephrotoxicity associated with STZ-induction. The DMET group marked the second highest MDA value, with $19.76 \mathrm{nmol} / \mathrm{mg}$ proteins, after the DC group, which was $19.96 \mathrm{nmol} / \mathrm{mg}$ proteins. Conversely, the DQ group indicated the significantly lowest kidney MDA value $(0.31 \mathrm{nmol} / \mathrm{mg}$ proteins $)$. Treatment with $A$. excelsa significantly decreased $(p<0.05)$ kidney MDA value to $1.92 \mathrm{nmol} / \mathrm{mg}$ proteins, which was not significantly different to those of the DQ and NC groups. On the other hand, the DC group showed a significant decrease $(p<0.05)$ in the GPx level, to $83.11 \mathrm{U} / \mathrm{mg}$ proteins, and an increase in SOD level to $11.11 \mathrm{mU} / \mathrm{mg}$, as compared with the NC group $(242.09 \mathrm{U} / \mathrm{mg}$ and $4.24 \mathrm{mU} / \mathrm{mg}$ protein, respectively). Meanwhile, SOD level was markedly increased in the DMET group $(12.79 \mathrm{mU} / \mathrm{mg}$ proteins) as compared to the DQ group, with $13.65 \mathrm{mU} / \mathrm{mg}$ proteins being the highest. It also was noted that both quercetin and $A$. excelsa treatments significantly increased the GPx concentrations (150.73 and 167.21 U/mg proteins, respectively), which were higher than that of the DMET group (137.38 \pm 0.62 $\mathrm{U} / \mathrm{mg}$ proteins).

Table 3 Kidney oxidative stress marker and antioxidant enzymes among experimental groups.

\begin{tabular}{cccc}
\hline \multirow{2}{*}{ Group } & Oxidative stress marker & \multicolumn{2}{c}{ Antioxidant enzymes } \\
\cline { 2 - 4 } & $\begin{array}{c}\text { MDA } \\
(\mathbf{n m o l} \text { MDA/mg protein) }\end{array}$ & $\begin{array}{c}\text { GPx } \\
(\text { U/mg protein) }\end{array}$ & $\begin{array}{c}\text { SOD } \\
\text { (mU/mg protein) }\end{array}$ \\
\hline NC & $1.40 \pm 0.03^{\mathrm{a}}$ & $242.09 \pm 0.09^{\mathrm{e}}$ & $4.24 \pm 0.39^{\mathrm{a}}$ \\
DC & $19.96 \pm 0.83^{\mathrm{b}}$ & $83.11 \pm 0.41^{\mathrm{a}}$ & $11.11 \pm 0.50^{\mathrm{c}}$ \\
DMET & $19.76 \pm 0.51^{\mathrm{b}}$ & $137.38 \pm 0.62^{\mathrm{b}}$ & $12.79 \pm 0.20^{\mathrm{d}}$ \\
DQ & $0.31 \pm 1.60^{\mathrm{a}}$ & $150.73 \pm 0.27^{\mathrm{c}}$ & $13.65 \pm 0.20^{\mathrm{e}}$ \\
DAE & $1.92 \pm 0.55^{\mathrm{a}}$ & $167.21 \pm 0.40^{\mathrm{d}}$ & $8.47 \pm 0.60^{\mathrm{b}}$ \\
\hline
\end{tabular}

Values are presented as means \pm SEM. Superscripts ${ }^{\text {a,b,c,d,e }}$ in a column differ significantly at $p<0.05$. NC $=$ Normal control rats, $\mathrm{DC}=$ Diabetic control rats, $\mathrm{DMET}=$ Diabetic rats treated with metformin, $\mathrm{DQ}=$ Diabetic rats treated with quercetin, DAE = Diabetic rats treated with $A$. excelsa.

\section{GFR and kidney function parameters}

In order to determine the effects of the treatments on the kidney, the glomerulus filtrate rate (GFR) was measured. As depicted in Table 4, the GFR values in all groups decreased dramatically $(p<0.05)$ compared to the value in the NC group. The DC group showed lower GFR $(0.98 \pm 0.05 \mathrm{~mL} / \mathrm{min})$ than that in the NC group, $(2.62 \pm 0.14 \mathrm{~mL} / \mathrm{min})$. Among the treatment groups, the $A$. excelsa treatment gave the highest values of GFR, which was $(1.60 \pm 0.25 \mathrm{~mL} / \mathrm{min})$, compared with the DQ group $(1.28 \pm 0.05$ $\mathrm{mL} / \mathrm{min})$ and the DMET group $(1.34 \pm 0.20 \mathrm{~mL} / \mathrm{min})$. However, their values were not significantly different to the DC group, but significantly lower than that of the NC group $(2.62 \pm 0.14 \mathrm{~mL} / \mathrm{min})$.

Table 4 also shows a significant increase in serum creatinine $(92.50 \pm 3.54 \mu \mathrm{mol} / \mathrm{L})$, but a significant decrease in urinary creatinine $(6.81 \pm 0.13 \mathrm{mg} / \mathrm{dL})$ in the DC group, as compared to the NC group $(63.00 \pm 1.50 \mu \mathrm{mol} / \mathrm{L}, 94.09 \pm 2.31 \mu \mathrm{mol} / \mathrm{L}$, respectively). Meanwhile, serum creatinine of the DMET, DQ, and DMET groups $(72.00 \pm 1.00 \mu \mathrm{mol} / \mathrm{L}, 69.50 \pm 1.50,66.50 \pm 2.50 \mu \mathrm{mol} / \mathrm{L} \mu \mathrm{mol} / \mathrm{L}$, respectively) were significantly different to that of the $\mathrm{NC}$ group $(63.00 \pm 1.50 \mu \mathrm{mol} / \mathrm{L})$. In addition, total bilirubin of the diabetic groups returned to near normal levels in response to the treatments. Interestingly, A. excelsa improved the uric acid levels of diabetic rats to near normal volume, which was $146.14 \pm 5.45$ $\mu \mathrm{mol} / \mathrm{L}$. 
http://wjst.wu.ac.th

Table 4 Changes of GFR and kidney function parameters of experimental groups.

\begin{tabular}{|c|c|c|c|c|c|c|c|}
\hline \multirow[b]{2}{*}{ Group } & \multicolumn{7}{|c|}{ Parameter } \\
\hline & $\begin{array}{c}\text { GFR } \\
(\mathrm{mL} / \mathrm{min})\end{array}$ & $\begin{array}{c}\text { Serum } \\
\text { creatinine } \\
(\mu \mathrm{mol} / \mathrm{L})\end{array}$ & $\begin{array}{c}\text { Urinary } \\
\text { creatinine } \\
(\mathrm{mg} / \mathrm{dL})\end{array}$ & Albumin $(g / L)$ & $\begin{array}{c}\text { Urea } \\
(\mathbf{m m o l} / \mathbf{L})\end{array}$ & $\begin{array}{l}\text { Uric acid } \\
(\mu \mathrm{mol} / \mathrm{L})\end{array}$ & $\begin{array}{c}\text { Total } \\
\text { bilirubin } \\
(\mu \mathrm{mol} / \mathrm{L})\end{array}$ \\
\hline $\mathrm{NC}$ & $2.62 \pm 0.14^{\mathrm{a}}$ & $63.00 \pm 1.50^{\mathrm{a}}$ & $94.09 \pm 2.31^{\mathrm{c}}$ & $40.05 \pm 0.75^{b}$ & $9.90 \pm 0.30^{\mathrm{a}}$ & $145.65 \pm 2.75^{\mathrm{a}}$ & $1.05 \pm 0.95^{\mathrm{a}}$ \\
\hline $\mathrm{DC}$ & $0.98 \pm 0.05^{\mathrm{b}}$ & $92.50 \pm 3.54^{\mathrm{b}}$ & $6.81 \pm 0.13^{\mathrm{a}}$ & $36.15 \pm 3.25^{\mathrm{ab}}$ & $15.85 \pm 0.95^{\mathrm{c}}$ & $241.90 \pm 2.7^{b}$ & $2.40 \pm 0.20^{\mathrm{b}}$ \\
\hline DMET & $1.34 \pm 0.20^{\mathrm{b}}$ & $72.00 \pm 1.00^{\mathrm{a}}$ & $9.77 \pm 0.26^{\mathrm{a}}$ & $27.80 \pm 3.30^{\mathrm{a}}$ & $13.55 \pm 0.15^{\mathrm{bc}}$ & $242.25 \pm 0.15^{b}$ & $0.80 \pm 0.20^{\mathrm{a}}$ \\
\hline DQ & $1.28 \pm 0.09^{\mathrm{b}}$ & $69.50 \pm 1.50^{\mathrm{a}}$ & $26.22 \pm 0.01^{\mathrm{b}}$ & $28.15 \pm 0.85^{\mathrm{ab}}$ & $11.60 \pm 0.90^{\mathrm{ab}}$ & $224.40 \pm 4.30^{\mathrm{b}}$ & $1.65 \pm 0.15^{\mathrm{ab}}$ \\
\hline DAE & $1.60 \pm 0.25^{b}$ & $66.50 \pm 2.50^{\mathrm{a}}$ & $8.48 \pm 0.01^{\mathrm{a}}$ & $28.10 \pm 5.30^{\mathrm{ab}}$ & $12.85 \pm 0.45^{\mathrm{ab}}$ & $146.15 \pm 5.45^{\mathrm{a}}$ & $1.25 \pm 0.15^{\mathrm{a}}$ \\
\hline
\end{tabular}

Values are presented as mean \pm SEM. Superscripts ${ }^{\mathrm{a}, \mathrm{b}, \mathrm{c}}$ in a column differ significantly at $p<0.05$. NC $=$ Normal control rats, $\mathrm{DC}=$ Diabetic control rats, DMET $=$ Diabetic rats treated with metformin, $\mathrm{DQ}=$ Diabetic rats treated with quercetin, DAE $=$ Diabetic rats treated with $A$. excelsa.

\section{Kidney histology}

Figure 1 reveals the histological assessment of the kidneys of the treated rats. The kidney tissue section of the NC group represents a normal tissue-architecture of the glomeruli and kidney tubules (Figure 1A). However, the kidney structure of the DC group showed marked morphological disturbances. There were varying degrees of deterioration in the histological architecture, with apparent increase in glomeruli sizes, including congested capillary vessels, vacuolar degeneration of the tubules, hyaline casts, distorted cellular boundaries of tubules, and areas of extravasated blood cells. Severe tubular degeneration and tubular necrosis were also noted (Figure 1B). Similarly, all of the treated rats had kidneys with shrunken glomeruli. Figure 1C shows equally severe changes in the proximal convoluted tubules, which consisted of cytoplasmic vacuolation of tubular epithelial cells and cellular swelling were markedly observed in the DMET group. The rats of this group displayed no observable improvement in the histological alterations of the glomeruli and tubules. Some irregular capillaries, in part attached to Bowman's capsule, were noted among the DQ group (Figure 1D). However, it was observed that the degree of necrosis of the tubular epithelium of the kidney was minimal in the DAE group. The diabetic rats treated with $A$. excelsa presented near-normal glomeruli and tubules (Figure 1E). The DAE group revealed nearly-normal renal architectures with minimal alterations, without hyaline casts, no extravasated blood cells, and reduced glomerular congestion. 

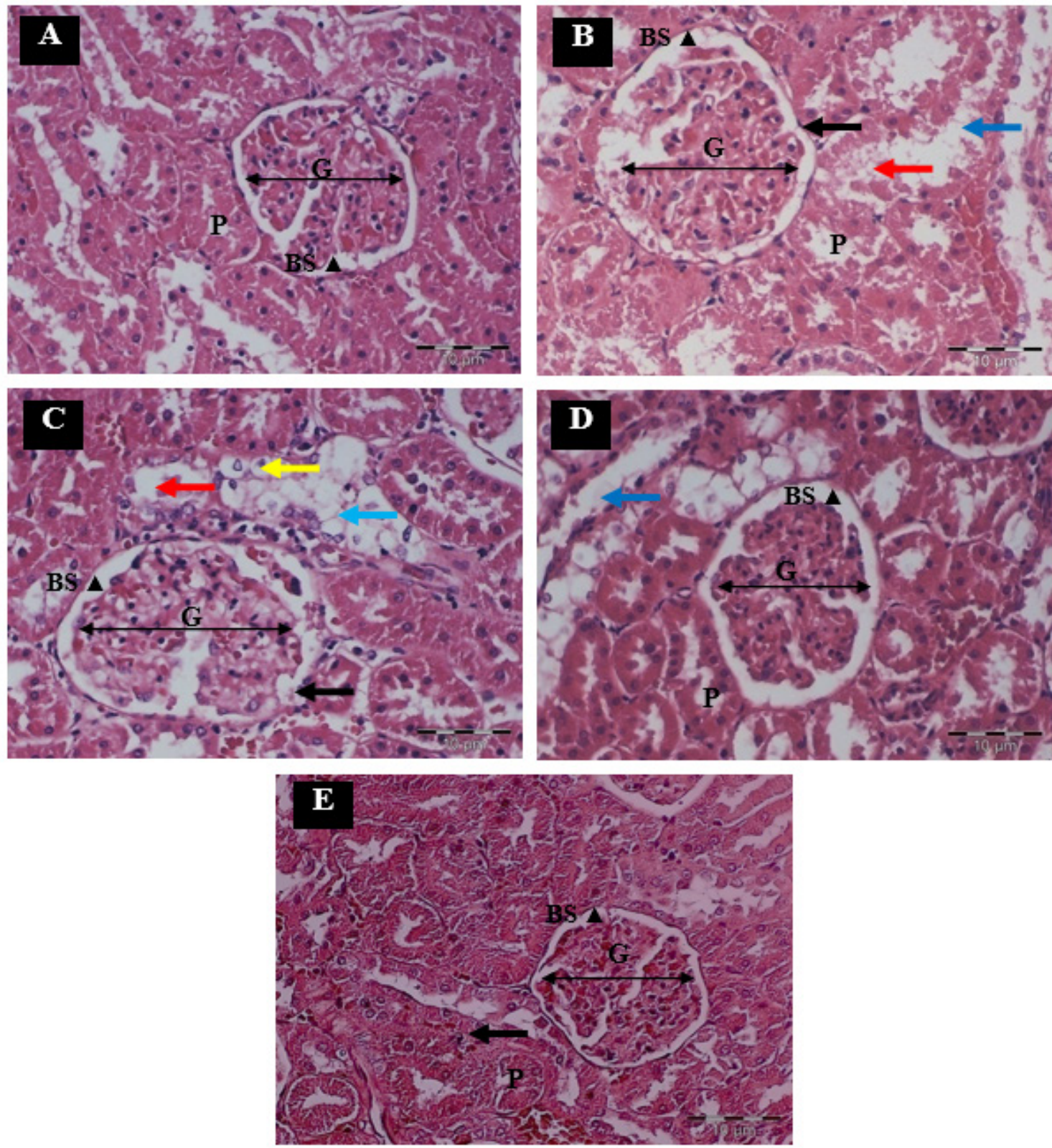

Figure 1 Light photomicrographs of glomeruli and renal tubules in rat kidneys. (A) The NC group showing normal glomeruli $[\mathbf{G}]$ with Bowman space $[\mathrm{BS} \mathbf{\Delta}]$ and proximal convulated tubules $[\mathbf{P}]$, (B) the DC group depicting a glomerulus $[\mathbf{G}]$ with irregular capillaries [black arrow] and tubular necrosis [red arrow], (C) the DMET group showing the lumina of the tubules was closed with swollen epithelial cells [yellow arrow], (D) the DQ group revealing the degree of necrosis of the tubular epithelium was lessened by quercetin extract, but capillary loops were poorly defined [the blue arrow], and (E) the DAE group presenting near-normal glomeruli and tubules (magnification $400 \times$ ). 


\section{Discussion}

Fasting blood glucose

Hyperglycemia, or increased blood glucose, are the hallmark signs of DM. In this study, the DC group showed a significant increase in FBG levels (Table 1). The results herein confirmed that induction of STZ at $60 \mathrm{mg} / \mathrm{kg}$ bwt causes hyperglycemia in rats [39]. The FBG levels were decreased following treatment with quercetin and $A$. excelsa. The ability of quercetin to reduce blood glucose levels in rat models has been reported by Alnahdi et al. [40]. Moreover, it has been reported that quercetin delayed the digestion of carbohydrates in the small intestine [41,42]. Previous studies also documented that plant active compounds are very useful in achieving optimal blood glucose control $[43,44]$. Treatment with $A$. excelsa extract improved the FBG levels in the STZ-treated rats. Similar findings were reported by Nurdiana et al. [45] and Nurul Izzati et al. [25]. The ability of $A$. excelsa in reducing FBG levels might be at least partially contributed to by its ability to increase plasma insulin levels [25,44]. Other contributing factors, including insulin sensitivity, reaction of glucose transporter, and glucose metabolism in the liver, require further evaluation.

\section{Kidney oxidant and antioxidant levels}

The study indicated that kidney MDA and SOD levels increased, whereas the concentration of GPx decreased, in the DC group (Table 3). The increase of SOD levels in kidneys of diabetic rats indicate the presence of antioxidant defense against oxidative stress. Other than that, previous studies also demonstrated that STZ treatment resulted in a lower anti-oxidant defense to protect kidney cells against ROS $[46,47]$. STZ is reported to promote lipid peroxidation production, which is a factor for renal injury and DN pathogenesis [10,19,48]. Results showed that the levels of SOD and GPx levels were significantly increased in the renal systems of both DMET and DQ treated groups. The DQ group indicated lower values of MDA compared with the NC group. Meanwhile, the MDA levels of the DAE group were reduced to the levels of the NC group. The findings implied that quercetin and $A$. excelsa extract improve antioxidant balance and have the ability to cope with renal oxidative stress. In agreement with the present findings, it was documented that plants can restrain lipid peroxidation, since they contain high levels of antioxidants [49]. The renal therapeutic ability of high antioxidant content of medicinal plants was also proven previously in xanthone derivatives from Garcinia mangostana [50]. Previous experimental work on nephrotoxicity confirmed the efficacy of quercetin in reducing oxidative injury [51]. The renal therapeutic activities in A. excelsa extract and quercetin treatments could also be due to this antioxidant mechanism.

\section{GFR and kidney function parameters}

The GFR is the best indicator for renal function [52]. The results showed that the DC group had a lower GFR (Table 4). This finding is important, because low GFR implies the progression of a kidney disease [53], as well as reflecting the retreated effects on tubular hyper-reabsorption, which is a potent cause of nephropathy injury [54]. Therefore, low GFR in the DC group indicated the existence of endstage renal failure in STZ-treated rats [55]. Even though the results were not significant, the DMET, DQ, and DAE groups showed an increase in GFR levels as compared to the DC group, with the DAE group revealing the highest GFR among the 3 treated groups. This might suggest the potential of prolonged $A$. excelsa treatment in alleviating renal disease.

Renal function markers play important roles in the diagnosis of renal condition [56]. The results showed that the DC group had significantly increased serum creatinine and uric acid, as well as decreased serum albumin and urinary creatinine (Table 4). These observations support the idea that increased serum creatinine levels and decreased excretion of creatinine in the urine are indicators of the development of DN [57]. The results obtained in the DC group provided evidence of DN among the diabetic rats. However, the DC group also showed a significant increase in total bilirubin, which is a sign of overcoming the oxidative stress effect. Bilirubin has potent antioxidant properties, which were described by Zhu et al. [58]. Additionally, it was demonstrated that high bilirubin concentrations in serum were protective factors for the development of DN [59]. Other than that, significant increase of uric acid in the 
http://wjst.wu.ac.th

DC group predicts the association of diabetes with 'gout' problem. A previous study already mentioned that, most commonly, kidney disease can cause gout [60,61]. However, gout itself may also lead to kidney disease [62].

Meanwhile, the level of urine creatinine was markedly increased in the DQ group as compared with the DC group. The novel finding of this study was that treatments with quercetin and $A$. excelsa caused significant decreases in serum creatinine as compared with the DC group. Additionally, treatments of quercetin and $A$. excelsa showed an increment in total bilirubin and were predicted to have renal protection effects from DN. In fact, the increase of total bilirubin and the decline of serum creatinine levels are evidence of renal therapeutic effects in STZ-induced DN [58,59]. It is also worth mentioning that the levels of uric acid were significantly reduced in the $A$. excelsa extract treatment group as compared with the DC and DMET groups. This finding implies that both treatments preserve renal therapeutic effects. Similar findings also reported the benefits of plant flavanoids in reinstating diabetic renal functions in rats [63].

\section{Kidney histology}

High doses of STZ with persistent hyperglycemia are well-known to result in renal failure [64]. The results demonstrated that the DC group is associated with structural damage in the kidney. Hence, the histology study reaffirmed structural damages, which include glomerulosclerosis, the swelling of renal cells with severe tubular degeneration, necrosis, and widening of Bowman's capsule (Figure 1B). Therefore, the presence of glomerulosclerosis was a major indicator of renal failure and diabetic nephropathy (DN). In fact, similar pathological changes have been described in renal tubules and glomeruli following STZ treatment [65]. The DQ group showed comparable renal morphology to those observed in the DAE group. Inconsistent with the results obtained by Bashir et al. [66], the quercetintreated diabetic rats demonstrated attenuation of the kidney structure. Indeed, anti-apoptotic effects of quercetin on renal glomerular cell cultures have been reported previously $[67,68]$. The important finding of this study was that treatment with $A$. excelsa lessened the glomerular and tubular lesions. Thus, this study highlights the relevance of $A$. excelsa as an alternative therapeutic option for DN. Therefore, it is possible to suggest that $A$. excelsa and quercetin possess renal therapeutic effects.

\section{Conclusions}

The DC group showed disturbances in the levels of antioxidants, which were associated with decline in kidney function and structure. It is conceivable to claim that high FBG was responsible for renal injury and antioxidant imbalance in the DC group. Importantly, these findings were in support of the disruption of renal function parameters and renal morphology. Therefore, it shows that treatment with $A$. excelsa and quercetin were capable of managing oxidant and antioxidant balance in the kidney. Both of the DAE and DQ groups showed reduction in kidney MDA, with improvement of SOD and GPx levels. The $A$. excelsa treatment indicated high GPx levels after the NC group. However, the metformin treatment indicated high MDA levels, even though their SOD levels increased. Other than that, it can be concluded that antioxidant balance contributes to the preservation of renal function parameters and renal morphology in a diabetic rat model. The level of uric acid was higher in the DC and DMET groups, which indicates the possible risk of gout arthritis. Meanwhile, A. excelsa treatment enabled the reduction of uric acid levels to normal volume. Hence, it is suggested that the therapeutic potential of $A$. excelsa, especially in ameliorating kidney function, might be contributed to by the abundance of quercetin in the extract. Moreover, HPLC analysis in a previous study showed a high content of quercetin in $A$. excelsa extract [20].

\section{Acknowledgements}

This project was financially supported by the Fundamental Research Grant Scheme (600RMI/FRGS 5/3 (5/2014)) and the Faculty of Applied Sciences, Universiti Teknologi MARA (UiTM). 


\section{References}

[1] ID Federation. IDF Diabetes Atlas. $6^{\text {th }}$ ed. International Diabetes Federation, Brussels, 2013.

[2] ME Molitch, RA DeFronzo, MJ Franz, WF Keane, CE Mogensen, HH Parving, MW Steffes and American Diabetes Association. Nephropathy in Diabetes. Diabetes Care. 2004; 27, S79-83.

[3] AC Webster, EV Nagler, RL Morton and P Masson. Chronic kidney disease. Lancet 2017; 389, 1238-52.

[4] D Intiso. The rehabilitation role in chronic kidney and end stage renal disease. Kidney Blood Pres. Res. 2014; 39, 180-8.

[5] LS Hooi, LM Ong, G Ahmad, S Bavanandan, NA Ahmad, BM Naidu and MFM Yusoff. A population-based study measuring the prevalence of chronic kidney disease among adults in West Malaysia. Kidney Int. 2013; 84, 1034-40.

[6] S Aronoff, K Berkowitz, B Shreiner and L Want. Glucose metabolism and regulation: Beyond insulin and glucagon. Diabetes Spectrum 2004; 17, 183-90.

[7] LC Plantinga, DC Crews, J Coresh, ER Miller, R Saran, J Yee, E Hedgeman, M Pavkov, MS Eberhard, DE Williams and NR Powe. Prevalence of chronic kidney disease in US adults with undiagnosed diabetes or prediabetes. Clin. J. Am. Soc. Nephrol. 2010; 5, 673-82.

[8] MY Donath, SE and Shoelson. Type 2 diabetes as an inflammatory disease. Nat. Rev. Immunol. 2011; 11, 98-107.

[9] NR Hill, ST Fatoba, JL Oke, JA Hirst, CA O'Callaghan, DS Lasserson and FR Hobbs. Global prevalence of chronic kidney disease-a systematic review and meta-analysis. PloS One 2016; 11, e0158765.

[10] G Vessal, M Akmali, P Najafi, MR Moein and MM Sagheb. Silymarin and milk thistle extract may prevent the progression of diabetic nephropathy in streptozotocin-induced diabetic rats. Ren. Fail. 2010; 32, 733-9.

[11] V Lobo, A Patil, A Phatak and N Chandra. Free radicals, antioxidants and functional foods: Impact on human health. Pharmacogn. Rev. 2010; 4, 118-26.

[12] S Fakhruddin, W Alanazi and KE Jackson. Diabetes-induced reactive oxygen species: Mechanism of their generation and role in renal injury. J. Diabetes Res. 2017; 2017, 8379327.

[13] K Das and A Roychoudhury. Reactive oxygen species (ROS) and response of antioxidants as ROSscavengers during environmental stress in plants. Front. Environ. Sci. 2014; 2, 53.

[14] BK Tiwari, KB Pandey, AB Abidi and SI Rizvi. Markers of oxidative stress during diabetes mellitus. J. Biomarkers 2013, 2013.

[15] J Dennis and P Witting. Protective role for antioxidants in acute kidney disease. Nutrients 2017; 9, 718.

[16] S Chirumbol. The role of quercetin, flavonols and flavones in modulating inflammatory cell function. Inflammat. Allergy-Drug Targets 2010; 9, 263-85.

[17] Y Li, J Yao, C Han, J Yang, M Chaudhry, S Wang and Y Yin. Quercetin, inflammation and immunity. Nutrients 2016; 8, 167.

[18] RA Rifaai, NF El-Tahawy, EA Saber and R Ahmed. Effect of quercetin on the endocrine pancreas of the experimentally induced diabetes in male albino rats: A histological and immunohistochemical study. J. Diabetes Metabol. 2012; 3, 2.

[19] M Edremitlığlu, MF Andıç, DB Sayin, O Korkut and U Kisa. Quercetin, a powerful antioxidant bioflavonoid, attenuates renal dysfunction in long-term experimental diabetes mellitus. Marmara Med. J. 2011; 24, 88-99.

[20] NSNM Zin, N Hashim, N Samsulrizal and NS Azmi. The protective effect of Azadirachta excelsa leaves extract and quercetin treatment on the learning and memory impairments in relation with insulin and amylin levels in the brain of streptozotocin-induced diabetic rats. J. King Saud Univ. Sci. 2019; 31, 299-307.

[21] S Nurdiana, MK Shukri, EJ Jega and NS Izzati. Antidiabetic activity of Azadirachta excelsa extract on alloxan induced diabetic rats. Open Conf. Proc. J. 2013; 4, 49-52. 
http://wjst.wu.ac.th

[22] B Cui, H Chai, HL Constant, T Santisuk, V Reutrakul, CW Beecher, NR Farnsworth, GA Cordell, JM Pezzuto and AD Kinghorn. Limonoids from Azadirachta excelsa. Phytochemistry 1998; 47, 1283-7.

[23] NI Shafie, N Samsulrizal, NA Sopian, MA Rajion, GY Meng, MM Ajat and H Ahmad. Qualitative phytochemical screening and GC-MS profiling of Azadirachta excelsa leaf extract. Malays. Appl. Biol. 2015; 44, 87-92.

[24] S Nurdiana, AN Haziqah, MNE Khairunnisa, SN Izzati, Y Norashirene and IN Hilwani. Attenuation of pancreatic histology, hematology and biochemical parameters in Type 2 diabetic rats treated with Azadirachta excelsa. Int. J. Agr. Biosystems Eng. 2014; 8, 613-6.

[25] SN Izzati, S Nurdiana, A Hafandi, AHM Zakihalani, MJ Norashirene and MHS Khairiyah. Antioxidant and hypoglycemic activities of Azadirachta excelsa in diabetic rats. In: Proceedings of the IEEE Symposium on Business, Engineering and Industrial Applications 2013. Kuching, 2013, p. 63.

[26] MA Fortes, CH Pinheiro, L Guimarães-Ferreira, KF Vitzel, DA Vasconcelos and R Curi. Overload-induced skeletal muscle hypertrophy is not impaired in STZ-diabetic rats. Physiol. Rep. $2015 ; 3$, e12457.

[27] M Gurukar, S Mahadevamma and ND Chilkunda. Renoprotective effect of Cocciniaindica fruits and leaves in experimentally induced diabetic rats. J. Med. Food. 2013; 16, 839-46.

[28] Y Dong, T Jing, Q Meng, C Liu, S Hu, Y Ma, Y Liu, J Lu, Y Cheng, D Wang and L Teng. Studies on the antidiabetic activities of Cordycepsmilitaris extract in diet-streptozotocin-induced diabetic Sprague-Dawley rats. BioMed Res. Int. 2014; 2014, 160980.

[29] SN Mestry, JB Dhodi, SB Kumbhar and AR Juvekar. Attenuation of diabetic nephropathy in streptozotocin-induced diabetic rats by Punicagranatum Linn. leaves extract. J. Tradit. Complement. Med. 2017; 7, 273-80.

[30] RA Rifaai, NF El-Tahawy, EA Saber and R Ahmed. Effect of quercetin on the endocrine pancreas of the experimentally induced diabetes in male albino rats: a histological and immunohistochemical study. J. Diabetes Metab. 2012; 3, 1000182.

[31] PH Miranda-Osorio, AE Castell-Rodríguez, J Vargas-Mancilla, CA Tovilla-Zárate, JL Ble-Castillo, DE Aguilar-Domínguez, IE Juárez-Rojop and JC Díaz-Zagoya. Protective action of Carica papaya on $\beta$-cells in streptozotocin-induced diabetic rats. Int. J. Environ. Res. Public Health 2016; 13, 446.

[32] R Premanath, N Lakshmidevi, K Jayashree and RN Suresh. Evaluation of anti-diabetic effect of Trigonella foenumgraecum Linn. Leaf extract in streptozotocin induced diabetic rats. Int. J. Diabetes Develop. Countries 2012; 32, 138-44.

[33] NA Qinna and AA Badwan. Impact of streptozotocin on altering normal glucose homeostasis during insulin testing in diabetic rats compared to normoglycemic rats. Drug Des. Dev. Ther. 2016; 9, 2515.

[34] A Tahara, A Matsuyama-Yokono, R Nakano, Y Someya and M Shibasaki. Hypoglycaemic effects of antidiabetic drugs in streptozotocin-nicotinamide-induced mildly diabetic and streptozotocin-induced severely diabetic rats. Basic Clin. Pharmacol. Toxicol. 2008; 103, 560-8.

[35] AD Kandhare, KS Raygude, VS Kumar, AR Rajmane, A Visnagri, AE Ghule, P Ghosh, SL Badole and SL Bodhankar. Ameliorative effects quercetin against impaired motor nerve function, inflammatory mediators and apoptosis in neonatal streptozotocin-induced diabetic neuropathy in rats. Biomed. Aging Pathol. 2012; 2, 173-86.

[36] S Kimura, T Inoguchi, H Yokomizo, Y Maeda, N Sonoda and R Takayanagi. Randomized comparison of pitavastatin and pravastatin treatment on the reduction of urinary albumin in patients with type 2 diabetic nephropathy. Diabetes Obes. Metab. 2012; 14, 666-9.

[37] RN Hardwick, CD Fisher, MJ Canet, AD Lake and NJ Cherrington. Diversity in antioxidant response enzymes in progressive stages of human non-alcoholic fatty liver disease. Drug Metab. Dispos. 2010; 38, 2293-301. 
http://wjst.wu.ac.th

[38] H Eslami, RA Batavani, S Asri-Rezaei and R Hobbenaghi. Changes of stress oxidative enzymes in rat mammary tissue, blood and milk after experimental mastitis induced by $E$. coli lipopolysaccharide. Vet. Res. Forum 2015; 6, 131-6.

[39] KK Mali, RJ Dias, VD Havaldar and SJ Yadav. Antidiabetic effect of garcinol on streptozotocininduced diabetic rats. Indian J. Pharmaceut. Sci. 2017; 79, 463-8.

[40] HS Alnahdi, NO Ayaz, AM Mohamed, IA Sharaf and NM Alshehri. Modulating impacts of quercetin and/or lactoferrin on diabetic nephropathy and cardiomyopathy induced rats. Int. J. Pharmaceut. Res. Allied Sci. 2017; 6, 128-37.

[41] SH Jo, EH Ka, HS Lee, E Apostolidis, HD Jang and YI Kwon. Comparison of antioxidant potential and rat intestinal a-glucosidases inhibitory activities of quercetin, rutin, and isoquercetin. Int. $J$. Appl. Res. Nat. Prod. 2009; 2, 52-60.

[42] JH Kim, JM Kang, HN Choi, SM Jeong, YM Lee and JI Kim. Quercetin attenuates fasting and postprandial hyperglycemia in animal models of diabetes mellitus. Nut. Res. Pract. 2011; 5, 107-11.

[43] EA Mohamed, M., Ahmad, LF Ang, M Asmawi and MF Yam. Evaluation of $\alpha$-glucosidase inhibitory effect of $50 \%$ ethanolic standardized extract of Orthosiphonstamineusbenth in normal and streptozotocin-induced diabetic rats. Evid. Based Complement. Alternat. Med. 2015; 2015, 754931.

[44] C Serra-Barcellona, NC Habib, SM Honoré, SS Sánchez and SB Genta. Enhydrin regulates postprandial hyperglycemia in diabetic rats by inhibition of $\alpha$-glucosidase activity. Plant Foods Hum. Nutr. 2017; 72, 156-60.

[45] S Nurdiana, KM Shukri, JE Jega and SN Izzati. Lowering blood glucose effect of Azadirachta excelsa leaves extract. Nat. Prod. Indian J. 2013; 9, 363-6.

[46] PS Sellamuthu, P Arulselvan, S Kamalraj, S Fakurazi and M Kandasamy. Protective nature of mangiferin on oxidative stress and antioxidant status in tissues of streptozotocin-induced diabetic rats. ISRN Pharmacol. 2013; 2013, 750109.

[47] A Aboonabi, A Rahmat and F Othman. Antioxidant effect of pomegranate against streptozotocinnicotinamide generated oxidative stress induced diabetic rats. Toxicol. Rep. 2014; 1, 915-22.

[48] JC Jha, C Banal, BS Chow, ME Cooper and K Jandeleit-Dahm. Diabetes and kidney disease: Role of oxidative stress. Antioxidants Redox Signal. 2016; 25, 657-84.

[49] A Zarei, S Changizi-Ashtiyani, S Taheri and M Ramezani. A quick overview on some aspects of endocrinological and therapeutic effects of Berberis vulgaris L. Avicenna J. Phytomed. 2015; 5, 485-97.

[50] N Karim, N Jeenduang and J Tangpong. Renoprotective effects of xanthone derivatives from garcinia mangostana against high fat diet and streptozotocin-induced type II diabetes in mice. Walailak J. Sci. \& Tech. 2016; 15, 107-16.

[51] S Chaudhary, P Ganjoo, S Raiusddin and S Parvez. Nephroprotective activities of quercetin with potential relevance to oxidative stress induced by valproic acid. Protoplasma 2015; 252, 209-17.

[52] J Santos and LS Martins. Estimating glomerular filtration rate in kidney transplantation: Still searching for the best marker. World J. Nephrol. 2015; 4, 345-53.

[53] SC Thomson, A Kashkouli and P Singh. Glucagon-like peptide-1 receptor stimulation increases GFR and suppresses proximal reabsorption in the rat. Am. J. Physiol. Renal Physiol. 2013; 304, F137-F144.

[54] P Palatini, F Dorigatti, F Saladini, E Benetti, L Mos, A Mazzer, G Zanata, G Garavelli and E Casiglia. Factors associated with glomerular hyperfiltration in the early stage of hypertension. $\mathrm{Am}$. J. Hypertens. 2012; 25, 1011-6.

[55] EL Schiffrin, ML Lipman and JF Mann. Chronic kidney disease: Effects on the cardiovascular system. Circulation 2007; 116, 85-97.

[56] S Gowda, PB Desai, SS Kulkarni, VV Hull, AA Math and SN Vernekar. Markers of renal function tests. N. Am. J. Med. Sci. 2010; 2, 170-3.

[57] E Tynkevich, M Flamant, JP Haymann, M Metzger, E Thervet, F Vrtovsnik, P Houillier, M Froissart, B Stengel and JJ Boffa. Decrease in urinary creatinine excretion in early stage chronic kidney disease. PloS One 2014; 9, e111949. 
[58] B Zhu, X Wu, Y Bi and Y Yang. Effect of bilirubin concentration on the risk of diabetic complications: A meta-analysis of epidemiologic studies. Sci. Rep. 2017; 7, 41681.

[59] AC Boon, AK Lam, V Gopalan, IF Benzie, D Briskey, JS Coombes, RG Fassett and AC Bulmer. Endogenously elevated bilirubin modulates kidney function and protects from circulating oxidative stress in a rat model of adenine-induced kidney failure. Sci. Rep. 2015; 5, 15482.

[60] B Alvarez-Lario and J Macarron-Vicente. Is there anything good in uric acid? QJM: Int. J. Med. 2011; 104, 1015-24.

[61] G Ragab, M Elshahaly and T Bardin. Gout: An old disease in new perspective - A review. J. Adv. Res. 2017; 8, 495-511.

[62] CW Tsai, SY Lin, CC Kuo and CC Huang. Serum uric acid and progression of kidney disease: A longitudinal analysis and mini-review. PloS One 2017; 12, e0170393.

[63] A Arya, MM Al-Obaidi, N Shahid, MI Noordin, CY Looi, WF Wong and MR Mustafa. Synergistic effect of quercetin and quinic acid by alleviating structural degeneration in the liver, kidney and pancreas tissues of STZ-induced diabetic rats: A mechanistic study. Food Chem. Toxicol. 2014; 71, 183-96.

[64] DE Odiase and FA Ominiabohs. Protective effects of aqueous extract of cinnamon on diabetesinduced nephrotoxicity in wistar rats. J. Appl. Sci. Environ. Manag. 2017; 21, 504-8.

[65] M Pourghasem, H Shafi and Z Babazadeh. Histological changes of kidney in diabetic nephropathy. Caspian J. Intern Med. 2015; 6, 120-7.

[66] SO Bashir. Hepatoprotective role for quercetin in diabetic rats: Hypolipidemic and antioxidant effects. Med. J. Cairo. Univ. 2014; 82, 169-78.

[67] Y Ishikawa and M Kitamura. Bioflavonoid quercetin inhibits mitosis and apoptosis of glomerular cells in vitro and in vivo. Biochem. Biophy. Res. Comm. 2000; 279, 629-34.

[68] M Erboga, C Aktas, ZF Erboga, YB Donmez and A Gurel. Quercetin ameliorates methotrexateinduced renal damage, apoptosis and oxidative stress in rats. Ren. Fail. 2015; 37, 1492-7. 